\title{
El patrimoni natural a Borriana
}

\author{
Andrea Rosselló Planelles (cinctorres1985@hotmail.com) \\ RoBert Roselló Gimeno (rrosello514k@cv.gva.es) \\ Universitat de València
}

\section{Introducció}

Presentem en aquest article una visió de conjunt sobre l'estat del patrimoni natural al terme de Borriana des de l'òptica de la conservació, però sense abandonar els aspectes descriptius. Realitzar una recapitulació de la biodiversitat suposa certes dificultats. En primer lloc, la falta d'estudis especialitzats sobre la majoria d'aspectes de la vida silvestre a Borriana: tret de poques excepcions, no disposem de catàlegs faunístics locals sobre molts grups taxonòmics (insectes, mamífers, equinoderms, rèptils, etc.), ni d'altres organismes (fongs, algues, etc.). Al nostre país, ple a vessar d'escriptors aficionats a la literatura, és pràcticament inexistent la figura del naturalista aficionat amb bona formació i predisposició a investigar i publicar. També representen dificultats la naturalesa i els components canviants, amb el temps, dels ecosistemes, i que en una compilació generalista i d'extensió limitada a priori, només podem destacar el més representatiu o més important.

Per a no excedir-nos en l'ús de l'espai editorial, hem deixat fora els ecosistemes marins, tret de l'obligada menció d'algunes poques espècies. Finalment, volem destacar la importància que al nostre medi té el patrimoni rural, en indissoluble harmonia amb la natura, llaurada al llarg de segles de coexistència. Reivindiquem la «ruralitat», igual que defensem la «naturalitat». Ambdues constitueixen un binomi inseparable, amb un futur indissolublement unit.

\section{Medi físic i vegetació}

El nostre terme forma part de la unitat geomorfològica superior que anomenem la Plana, planura allluvial en forma de gegantesc hemicicle que abasta des de la torre Colomera, a Orpesa, fins a Almenara. Borriana pertany a la Plana Baixa, situada al sud del riu Millars, la nostra frontera nord. Els quasi cinquanta kilòmetres quadrats de terme estan solcats pel riu Sec, que desemboca en una zona palustre denominada històricament «estany de la Vila», hui Clot de la Mare de Déu, relíquia d'una antiga albufereta que contacta amb el delta dissimulat del Millars. Els dos rius han tingut un paper determinant en la configuració del solar del territori, en haver aportat els sediments al-luvials procedents de les terres de l'interior que l'han conformat. Al mateix temps que el terme s'ha endinsat en la mar, la línia de costa s'ha allunyat de les muntanyes litorals, en un vaivé en què han predominat els fenòmens sedimentaris sobre els erosius. Tot açò, ocorregut fonamentalment durant el plistocè i l'holocè, ha estat afavorit per una espècie d'escalonament geoestructural en direcció a la costa, provocat per una sèrie de falles, que condicionen el que s'anomena una gènesi 


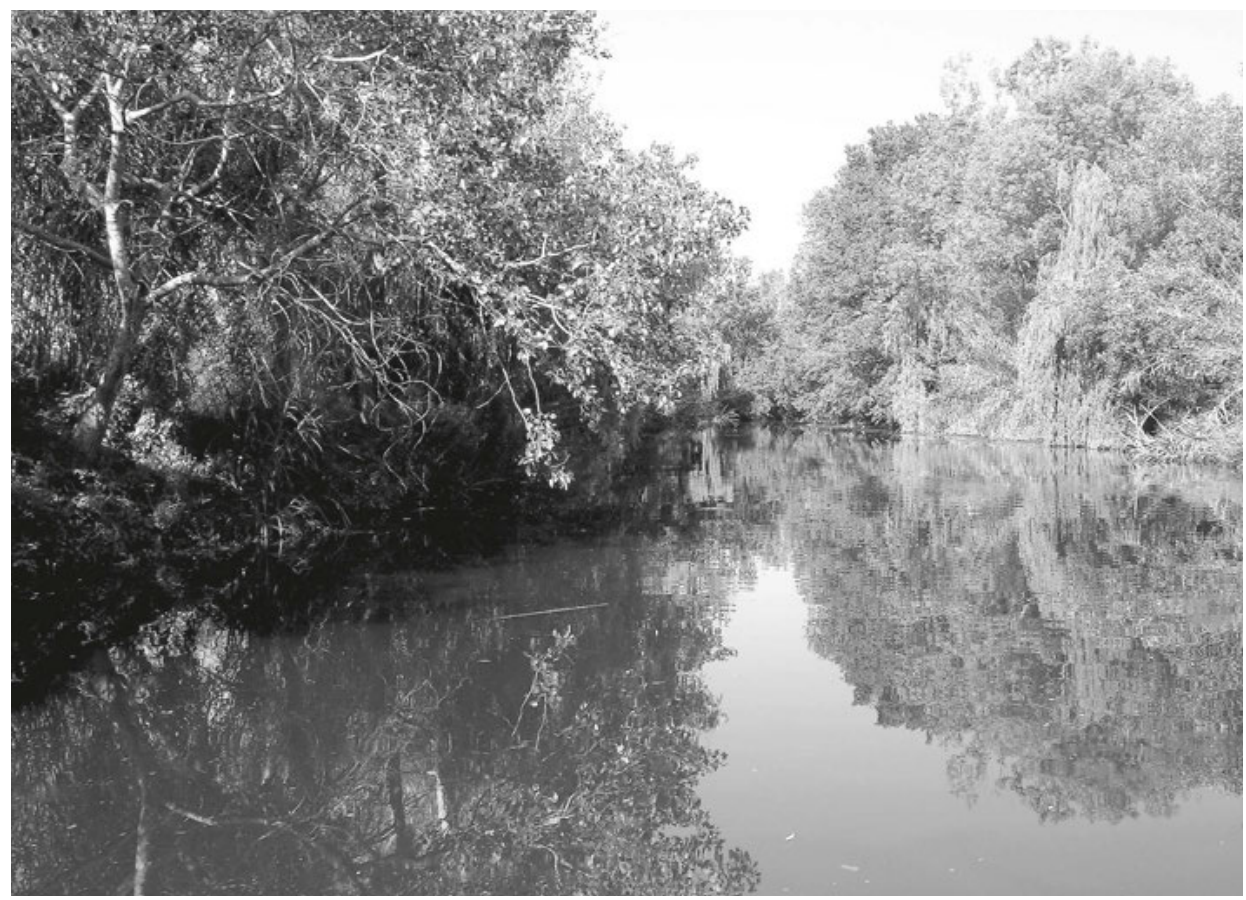

1. Comunitat forestal en galeria del Clot (Foto: els autors).

costanera per fractura, la qual explicaria, en part, la tendència actual a la submersió dels quasi deu kilòmetres de costa que hem hagut de protegir mitjançant espigons i esculleres.

D’altra banda, les condicions climatològiques són molt favorables per a la vida en general a causa, en bona part, de la influència reguladora de la mar. Les gelades hivernals que provoquen les esporàdiques incursions de vents siberians són, per fortuna, escasses i de curta duració; la temperatura mitjana anual voreja els $14-15^{\circ} \mathrm{C}$. En el llenguatge bioclimàtic, habitualment emprat pels botànics, direm que el nostre terme forma part de l'estatge termomediterrani sec.

En efecte, la precipitació mitjana anual presenta valors entre 400 i 500 mm, però repartits irregularment, car és durant els períodes equinoccials quan campegen les baixes pressions atmosfèriques; són força habituals els fenòmens de gota freda i les riuades, que han llaurat una espècie de por atàvica en el subconscient dels habitants de la Plana. La mediterraneïtat del nostre territori ve determinada per aqueixa coincidència dels mesos més calorosos amb els mínims de pluviositat anual, que posen a prova la capacitat d'adaptació i supervivència de la vida en qualsevol forma.

Tenint en compte les condicions bioclimàtiques adés exposades, trobem que la vegetació principal al terme de Borriana hauria de ser un carrascar o manifestar-se a través de qualsevol de les etapes de substitució, tan comunes als indrets que qualifiquem de «secà» (romerars, argelagars, etc.). Però, la realitat ens mostra que no és així, amb rares excepcions (vegeu més endavant el que diem a propòsit d'això en l'apartat sobre el 
Millars). La vegetació potencial que caracteritza el territori on vivim és una omeda, bosc amb dominància de grans arbres freatòfits de fulla caduca (malgrat això, no deixa de ser una vegetació plenament mediterrània) com ara els que a Borriana anomenem mosquiters (Ulmus minor), llidoners (Celtis australis), gatells (Salix atrocinerea), etc.; arbustos i lianes com ara els esbarzers (Rubus ulmifolius, R. caesius), heura (Hedera helix), cirerer de pastor (Crataegus monogyna), gavarrera (Rosa sempervirens) etc., i un estrat herbaci amb cresola (Arum italicum), fenàs de bosc (Brachypodium sylvaticum), més un llarg etcètera (Foto 1). Com s'explica l'existència d'un gran bosc exigent en humitat i nutrients sota les dures condicions que imposa el nostre clima durant una part de l'any? La resposta es troba als sòls del terme - i de la Plana en general-, majoritàriament profunds, que funcionen com una esponja per la capacitat de retenció d'aigua, generadora d'una important reserva aqüífera que serà vital durant els mesos menys afavorits per les pluges amb temperatures més elevades.

Pot semblar paradoxal parlar d'un bosc com a «vegetació característica» d'un territori on aparentment no s'aprecia cap tipus de vegetació forestal. I és en aquesta segona paradoxa on trobem una altra peculiaritat del nostre medi: els esforços dels pobladors ancestrals de la Plana per a aconseguir l'habitabilitat d'aquestes terres i aprofitar-ne l'excepcional fertilitat, ideal per a practicar l'agricultura en qualsevol modalitat.

\section{Història}

El nostre terme probablement ja en època romana tenia una configuració pareguda a l'actual, però amb moltes més zones de marjal i boscoses verges, un autèntic paradís per a la fauna i els caçadors. Quan tractem d'illuminar amb coneixements les foscors que envolten els nostres orígens, sabem que hi ha grans llacunes que probablement sempre romandran per resoldre. Però, allà on falten o escassegen les dades, tampoc no seria desencertat especular que la progressiva colonització i sistemàtica transformació del paisatge primigeni per a convertir-lo en l'actual regadiu (desforestació, incendis controlats, construcció de sistemes de reg - pous, séquies, etc.—, cultiu i aclimatació d'espècies foranes, etc.) degué començar ja en època romana, i amb interrupcions més o menys llargues es devia accelerar i consolidar a partir de la fundació de la ciutat musulmana de Borriana al segle IX.

La preponderància actual dels cultius és incompatible amb la presència d'un bosc, el qual queda relegat a allò que anomenem «vegetació potencial», concepte ben intuïtiu d'altra banda. L'exhaustiva explotació agrícola i ramadera al llarg dels segles marca la història particular del nostre territori; l'antropització ha condicionat de manera tan decisiva el nostre patrimoni natural, com poden fer-ho la climatologia o l'edafologia. Actualment, l'única representació que ens queda de la primitiva i potencial vegetació natural i general del terme és l'omeda que tenim al paratge natural del Clot, també molt antropitzat. D'altra banda, la vegetació particular de la franja costanera i la d'algunes zones de la frontera del Millars s'ha mantingut incòlume durant segles, tot i que en els darrers cinquanta anys ha patit un fortíssim retrocés i, en molts casos, simplement ha desaparegut.

Les referències escrites més antigues que tenim sobre el patrimoni rural i natural borrianenc són del segle XVI, i les trobem a la crònica de Viciana (llibre tercer) on el nostre avantpassat ens deixà alguns apunts ben coneguts, com ara quan menciona l'estany de la 
Vila, o quan parla de «la caza de puercos javalines; de liebres, de conejos de francolines y otras aves de vuelo». Tot sembla suggerir que ja aleshores la primigènia fisonomia del terme havia evolucionat molt, que ja apareixia com un extens regadiu, encara que naturalment sense la presència dels cultius comercials a gran escala que vindrien 200 anys després, com les moreres (cuc de seda), la canya de sucre, el cànem i la citricultura. Reproduïm tot seguit un text descriptiu sobre com imagina un de nosaltres (R. Roselló, 2003: 365-366) que podria ser aqueix paisatge en època de Viciana:

A les zones perifèriques als aiguamolls i llacunes hi hauria extensos senillars i bovalars, que en primavera s'encendrien de lliris i esclafirien de cants de granotes. Els mosquits i altres insectes eren el revers de tan idíllica estampa. Més a prop de la costa, sobre sòls més salnitrosos, els senillars donarien pas a les jonqueres, que probablement cobririen zones prou extenses en la voramar de l'època. Aquests ecosistemes costaners, tradicionalment qualificats com a insalubres, hui serien zones protegides pel seu alt índex de biodiversitat...

La vegetació potencial sobre sòls d'al·luvió era i és una omeda, com la que trobem hui, fragmentàriament, al Clot. És molt probable que xicotetes masses forestals d'oms i llidoners, i de bardisses amb albarzers, heura, cirerers de pastor, rosers silvestres, etc., poblaren els ja aleshores retalls verges que quedaven i els marges dels camps.

En època de Viciana ja es cultivava la canya (Arundo donax), espècie exòtica d'origen possiblement asiàtic: «nacen y críanse en este término muchas cañas largas y muy recias, que después de las de la ribera del Júcar son las mejores de España (M. de Viciana, 1564: 326). Les canyes són un element característic del nostre paisatge de regadiu, que formen $-\mathrm{i}$ formavenespessos i impenetrables canyars a les vores de les séquies, rius, etc.

La canya (Arundo donax) és cultivada principalment per la condició d'eina útil per a quasi tot, perquè aporta múltiples serveis a l'agricultura i, després de tants anys, és ja part inseparable del paisatge mental i físic dels habitants de la Plana, del nostre folklore, jocs infantils i tradicions en general (canuts, pàmpol-figos, barquetes, falques, pèrgoles, canyissos, canyes de pescar, etc.). Però cal no oblidar que des d'un punt de vista ecològic és un autèntic «alien», considerada actualment a escala mundial com una espècie invasora $\mathrm{i}$ agressiva, perquè els canyars — ni el foc controlat basta sovint per a aconseguir exterminarlos-, ocupen els biòtops de la vegetació autòctona, particularment de les omedes, a la qual fins i tot desplacen i n'impedeixen la regeneració.

\section{Publicacions}

Per a conèixer la biodiversitat d'un territori, ens hauríem de basar en tres tipus de fonts d'informació: 1) Estudis monogràfics (articles i/o llibres), realitzats generalment per especialistes. 2) Citacions d'espècies referides a la nostra localitat, aparegudes en articles o revistes d'àmbit científic i contingut més general. I, 3): Observacions personals o comunicacions verbals fiables de terceres persones. En aquest paràgraf ens referirem a les dues primeres exclusivament. És fàcil observar com s'incrementen notablement les publicacions a partir de la dècada dels 80 , com a conseqüència de la implantació dels estudis universitaris de Biologia a la Universitat de València i d'un canvi de mentalitat 
sorgit en la societat espanyola, d'una major sensibilitat envers els temes naturalístics. Amb tot, en l'àmbit local ens trobem davant d'escassa bibliografia, amb les excepcions de les especialitats de malacologia, ornitologia i botànica (florística i fitosociologia).

Entre els autors que han aportat dades i novetats florístiques i faunístiques (vegeu-ne la bibliografia) dins dels clàssics trobem Rossmassler (1835), Azpeitia (1933) i Gasull (1971, 1975, 1981). Més recents tenim Pardo (1984), Roselló i Peris (1990, 1991), Roselló (1997, 2004, 2005a, 2005b, 2007: 229-232), i Baixeras, J. i altres (2006: 82, 88, 92). Mereixedors d'una menció singular són Martínez-Ortí i Cádiz (2012), que van descobrir i descriure recentment una nova espècie de mol·lusc marí trobada davant les costes de Borriana.

Les publicacions monogràfiques en forma d'articles o llibres, on l'autor parteix d'un plantejament de catalogació més o menys exhaustiu i profund del tema que tracta a escala local, són escasses i centrades sobre els mateixos grups taxonòmics que hem indicat adés. Són les següents: Collado i Pardo (1985), Andrés (1991), Navarro (1991) i Roselló (1988, 1990, 1991, 2007, 2008a, 2008b). Són també importants els estudis de seguiment sobre l'avifauna del Clot realitzats per Castany (2007 i següents).

\section{Espais naturals}

Ja ens havíem referit al canvi de sensibilitat social que sorgeix durant el darrer quart de segle. L'aparició en escena de les teories de la globalització, de les quals n'és part fonamental l'ecologisme, és una revolució nascuda de les contradiccions de les societats més desenvolupades que constaten la limitació dels recursos no renovables i que la degradació mediambiental no només és autodestructiva, sinó que pot ser fins i tot irreversible. L'ecologisme planteja un problema d'àmbit planetari (apocalíptic per als adversaris, realista per als partidaris), amb moltes terminals locals. El canvi de sensibilitat i de paradigma es generalitza (fins i tot es vulgaritza) i així també acaba per aparèixer en l'ideari i els programes dels partits polítics. A la Comunitat Valenciana es creà una Conselleria de Medi Ambient, i a escala local tenim també la regidoria corresponent: una novetat esperançadora per als qui havíem conegut temps d'indiferència.

El deteriorament dels ecosistemes naturals, provocat pel creixement exponencial de la població humana, es vol compensar en les societats modernes amb les figures proteccionistes. En atenció als valors naturals, a Borriana tenim actualment quatre d'aquests espais reconeguts per les administracions autonòmica i local (dos dels quals, compartits amb Nules, Almassora i Vila-real), tots ells «de frontera» o situats marginalment a la franja costanera del terme; i tres dels quals figuren al Catàleg de zones humides de la Comunitat Valenciana. Per limitació d'espai, en remarcarem breument la importància sense entrar-hi en molt de detall.

\subsection{El Clot de la Mare de Déu}

Fou el primer espai natural d'aquestes característiques que es va reconèixer a la província de Castelló, per acord del Consell, de 8 de febrer de 2002, on es declarava el Clot Paratge Natural Municipal (DOGV 4191).

El Clot no és valuós per guardar espècies rares o úniques, sinó considerat en tot el conjunt, i també per la simbologia que té. Resultat d'una conjunció de fenòmens 


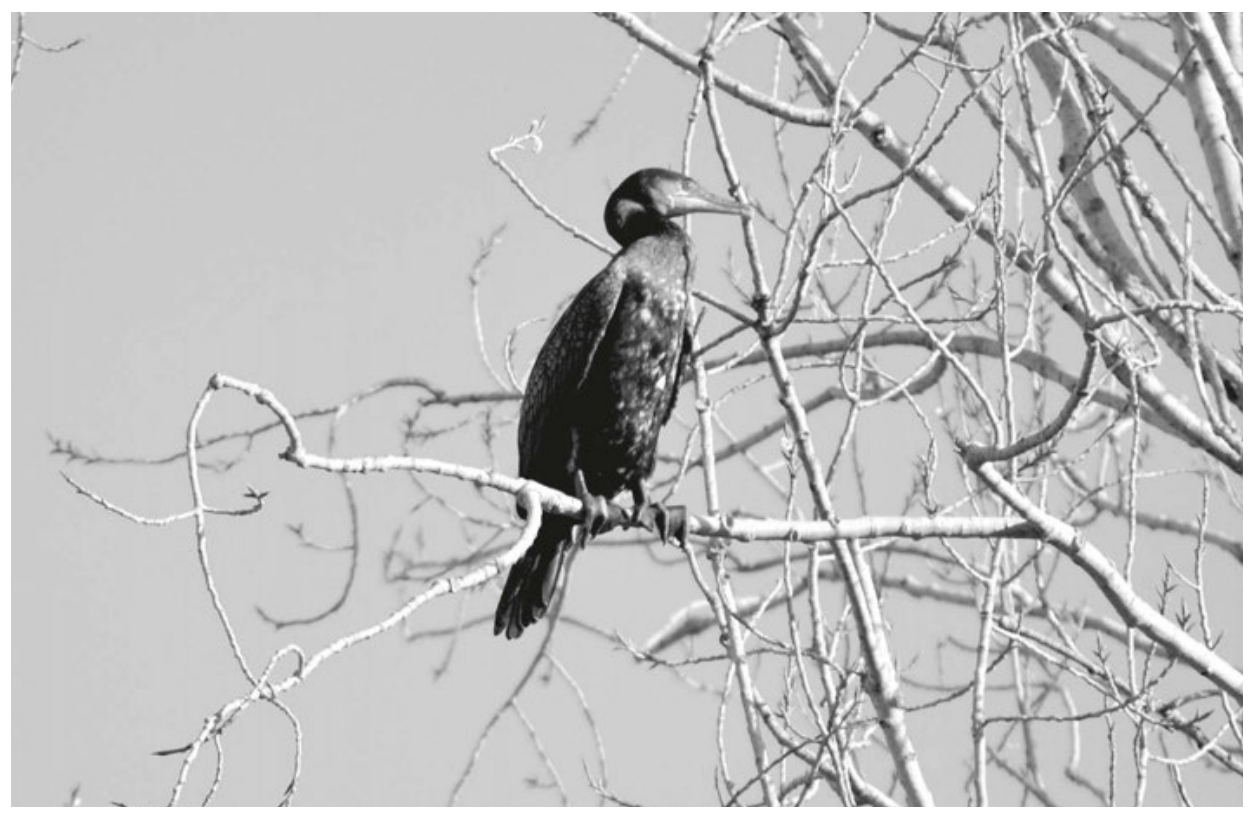

2. Corb marí (Phalacrocorax carbo) en un arbre del Clot (Foto: els autors).

hidrogeològics, botànics, etc., i posseïdor d'una notable biodiversitat, és l'única llacuna del terme que ha sobreviscut el pas del temps (antigament n'hi havia hagut altres) ja que s'alimenta de brolladors subterranis i ocupa l'últim tram del paleollit (originat durant el plistocè) d'un riu sec que baixava de la serra d'Espadà i, de forma intermitent, descarrega riuades a la mar. A l'esmentat valor relicte, cal afegir-hi els simbòlics, ja que la vegetació forestal dels marges (fonamentalment l'omeda), és el bosc representatiu de la vegetació potencial del terme de Borriana i de la Plana sencera (vegeu el segon apartat) (Foto 1). El paratge suma també valors sentimentals, religiosos i estètics molt axiomàtics.

De la mateixa manera que entre els diferents ecosistemes vegetals que s'hi poden trobar els més peculiars són els forestals, creiem que faunísticament tenen especial rellevància els peixos i les aus. Els rumors sobre la presència d'endemismes com ara el fartet (Aphanius iberus) o del samaruc (Valencia hispanica) no són creïbles (segurament hi ha hagut confusió amb la gambúsia), per incompatibilitat amb l'actual eutrofització de les aigües. En èpoques remotes no podem descartar-ne presència, almenys del fartet. D'altra banda, el paratge ha estat sempre un bon lloc per a les anguiles (Anguilla anguilla) que actualment passen per un mal moment, i fa anys l'ICONA el va repoblar de tenques (carpa, Cyprinus carpio), tot i que hui està prohibida la pesca al paratge. També hi ha el peix roig (Carassius auratus), etc., i especial menció mereix un peixet de gran interès faunístic com és el mossegadoret o gatet — «colmilleja» en castellà-(Cobitis paludica).

Quant a l'avifauna autòctona, entre les aus nadadores abunden la polla d'aigua (Gallinula chloropus) i l'escabussonet (Tachybaptus ruficollis); també el coll-verd (Anas platyrrhynchos) i, més escassa, la fotja (Fulica atra). D'entre les nombroses espècies d'aus 
arborícoles destacaríem el blauet (Alcedo atthis), mereixedor a ser símbol del paratge pel colorit i les habilitats pescadores. El corb marí (Phalacrocorax carbo) (Foto 2), au bàsicament marina, últimament l'hem vist regularment en època hivernal pescar (tenques i llisses -Mugil sp.) i descansar sobre les branques dels arbres del paratge.

Entre el Clot i el camí de les Salines es va construir, l'any 2010, un hàbitat artificial de $70.000 \mathrm{~m}^{2}$ per a albergar-hi un tímid queloni al qual no pocs consideren símbol de les marjals: les tortugues d'aigua autòctones (Emys orbicularis). Procedents de la reserva afectada per la futura urbanització del PAI de Sant Gregori, l'operació fou fruit d'un conveni entre el nostre consistori i la Conselleria. La tortuga d'aigua no era gens rara a les zones de marjal de Borriana, i actualment està amplament protegida per la legislació espanyola i valenciana. Cal no confondre-la amb la tortugueta de Florida (Trachemys scripta scripta), animal domèstic que irresponsablement alguns acaben per abandonar al Clot. Durant els anys 2006 i 2010 tècnics de la Conselleria van haver d'instal-lar-hi trampes per a retirar aquesta espècie competidora de la tortuga autòctona, que pot arribar a fer quasi dos pams.

\subsection{Desembocadura del Millars}

És paratge protegit (el segon per ordre cronològic del nostre elenc), per obra d'un decret del Consell, publicat al DOGV núm. 4988, d'abril de l'any 2005. El Pla d'usos i gestió del paratge és més recent i s'aprovà en el Decret 169/2012, de 9 de novembre.

De la importància d'aquest indret dóna idea el fet que de la gestió s'encarrega un consorci format per Borriana, Almassora, Vila-real, la Diputació i la Conselleria. I també les importants figures proteccionistes que recauen sobre ell: zona d'especial protecció per a les aus (ZEPA), refugi de caça, i lloc d'interès comunitari (LIC) de la Comunitat Valenciana.

Si el Clot és interessant especialment per la vegetació forestal i la condició de llacuna relicta, la desembocadura del Millars és especialment important per a la conservació de les aus. Particularment el tram final, amb les Goles (separades de la mar per una barrera de grava), entre les quals hi ha dos illots (històricament coneguts com a «illa del Sargat» o «els Alters», per la sarga - Salix elaeagnus - que hi abunda), i tota la zona està folrada d'extensa vegetació helofítica (espessos senillars i bovalars) que constitueixen l'amagatall de cert tipus d'avifauna que requereix l'aïllament de les zones humides per a refugiar-se, alimentar-se i nidificar (Foto 3).

Des d'un punt de vista botànic, valorem com a molt interessant la presència en certs trams del riu de brolles de romer (Rosmarinus officinalis), pròpies d'una sèrie de vegetació que no és la potencial a la Plana Baixa, i que en certs indrets arriba molt a prop de la mar, amb un marcat caràcter de «vegetació illa», si es té en compte l'entorn. Hi trobem romer (Rosmarinus officinalis), argelagues (Ulex parviflorus), timonet (Thymus vulgaris), sempreviva (Helichrysum stoechas), timó mascle (Teucrium belion, T. capitatum), càdecs (Juniperus oxycedrus), etc. Aquestes formacions es fan sobre sòls molt eixuts i assolellats, estabilitzats i elevats sobre el fons de rambla del llit del riu (on creixen altres tipus de vegetació específica), l'origen dels quals pot ser de terrassa fluvial o de ventall al·luvial, principalment (Foto 4).

La riquesa natural del Millars és important. Podeu trobar-ne exhaustiva informació en el web <http://www.consorciriumillars.com>. 


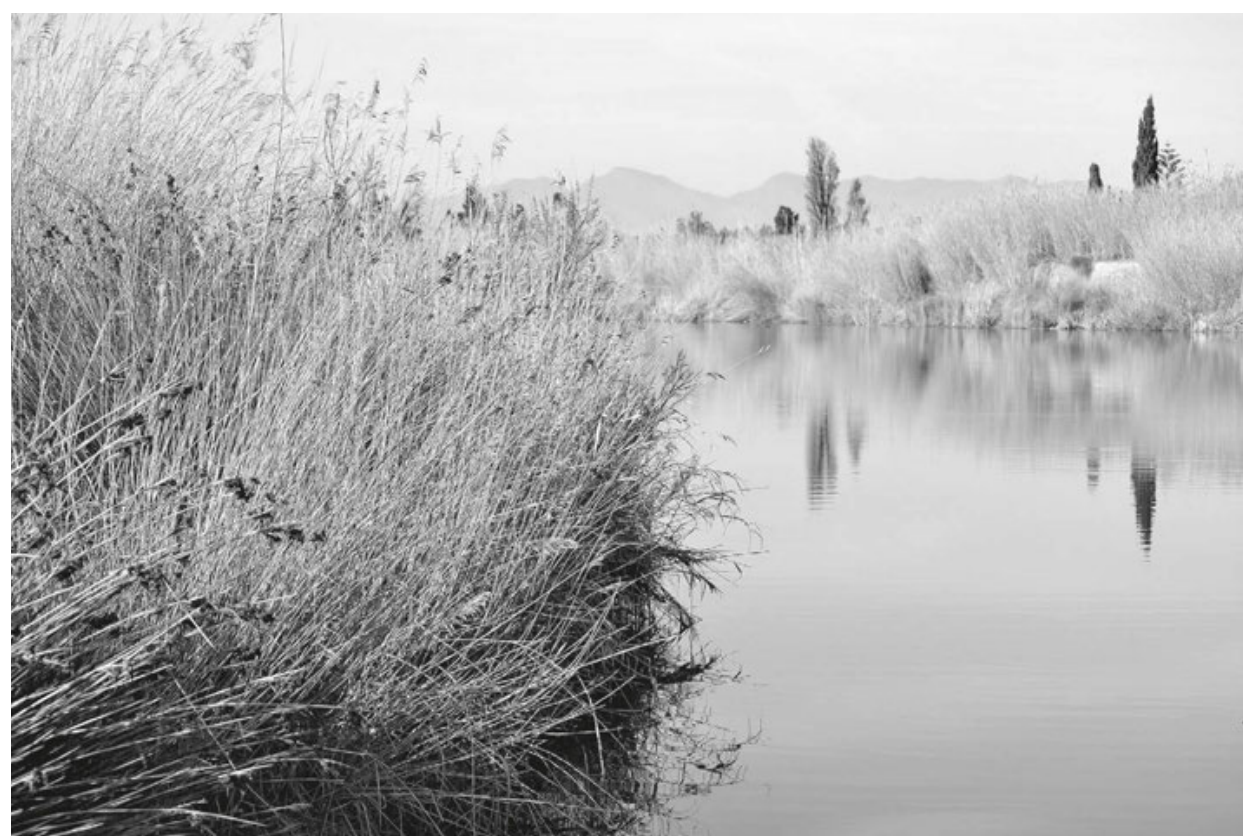

3. Vegetació helofítica a les Goles del Millars (Foto: els autors).

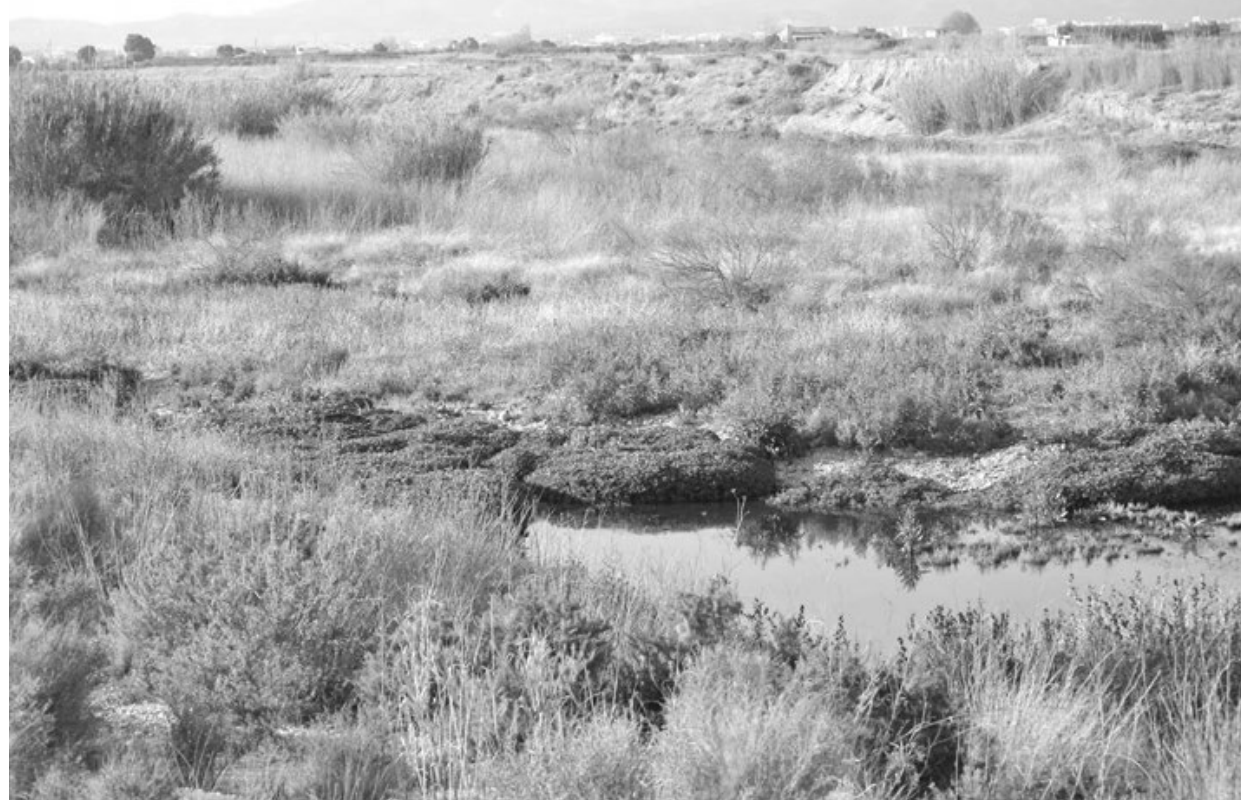

4. Riu Millars, contrast entre la vegetació de Rosmarinion (primer plànol i rerefons) i la vegetació de fons de rambla (Foto: els autors). 


\subsection{Microreserva de flora dunar de l'Arenal}

Espai natural, aprovat pel Consell l'11 de març de 2008, i declarat oficialment com a microreserva de flora en el DOGV del 9 d'abril de 2008. Potser siga el més desconegut, perquè no gaudeix de l'espectacularitat paisatgística del Clot ni tampoc de la seua fotogènia. La Conselleria, a més de delimitar la zona i protegir-la, hi ha realitzat tasques de repoblament de l'ecosistema dunar amb introducció d'espècies adients, com ara el lliri de mar (Pancratium maritimum), etc. El nostre ajuntament hi col-labora amb la neteja i custòdia de la zona.

Com el mateix nom indica, el valor hi radica en el contingut florístic, a base d'espècies psammòfiles (arenícoles) i halòfiles (adaptades a la salinitat del sòl) costaneres. Són també ecosistemes relictes, els que més destrucció han patit en els darrers cinquanta anys al nostre litoral mediterrani, en haver entrat en conflicte territorial amb l'expansió de l'anomenat turisme de platja; i l'Arenal de Borriana, malgrat el raquitisme turístic en infraestructures, tampoc ha representat cap excepció a aquesta lamentable tendència.

La microreserva de l'Arenal conté dos tipus principals d'ecosistemes vegetals, representatius del que hi havia antigament. En primer lloc, encarant la mar i els vents, una barrera de xicotetes dunes, que a sotavent contacten bruscament amb una depressió saulonosa que s'ompli d'aigua de mar els dies de «llevantà» i que, en evaporar-se, deixa un solatge salnitrós. Hi existeixen diferents tipus de vegetació i plantes característiques adaptades a aquestes condicions difícils per a la vida. Entre les plantes psammòfiles, la comunitat més interessant la constitueix la rara blanquinosa (Otanthus maritimus) (Foto 5), en companyia del melgó marí (Medicago marina), el lot blanc (Lotus creticus), el card marí (Eryngium maritimum), el rave marí (Echinophora spinosa), etc. La vegetació halòfila de la rereguarda és fonamentalment una jonquera marina, amb joncs (Juncus acutus, Juncus maritimus, Schoenus nigricans), i la interessant lletugueta de mar (Limonium angustebracteatum), entre altres.

\subsection{La marjal de Nules-Borriana}

Amb la desembocadura del Millars i el Clot, la marjal de Nules-Borriana està inclosa, des de setembre de 2002, en el Catàleg de zones humides de la Comunitat Valenciana, si bé encara no se n'ha redactat el corresponent pla d'usos i gestió.

Es tracta d'una zona de marjal, però tradicionalment habitada, on els sequiols, amb grans oscil-lacions estacionals en el nivell d'aigua, drenen els sobrants a la mar. Probablement, el més valuós que trobem als sequiols siga la rica vegetació aquàtica formada per rizòfits i mesopleustòfits i, per descomptat, els bovalars, senillars marginals, i tota la cohort de vegetació. Plantes com la pota de bou (Nymphaea alba), en altre temps també present al Clot, i la utriculària (Utricularia australis), una carnívora aquàtica que només coneixem de la marjal de Nules — no es troba actualment a Borriana-, i moltes més altres plantes rares, així com la tortuga d'aigua (Emys orbicularis) i la seua presa predilecta, l'antigament abundant gambeta de sequiol (prob. Dugastella valentina $-\mathrm{o}$ Atyaephyra desmaresti?-), diverses aus palustres i la rica odonatofauna (libèlllules), lligada als sequiols i a les zones humides en general, justifiquen àmpliament la figura de protecció. 


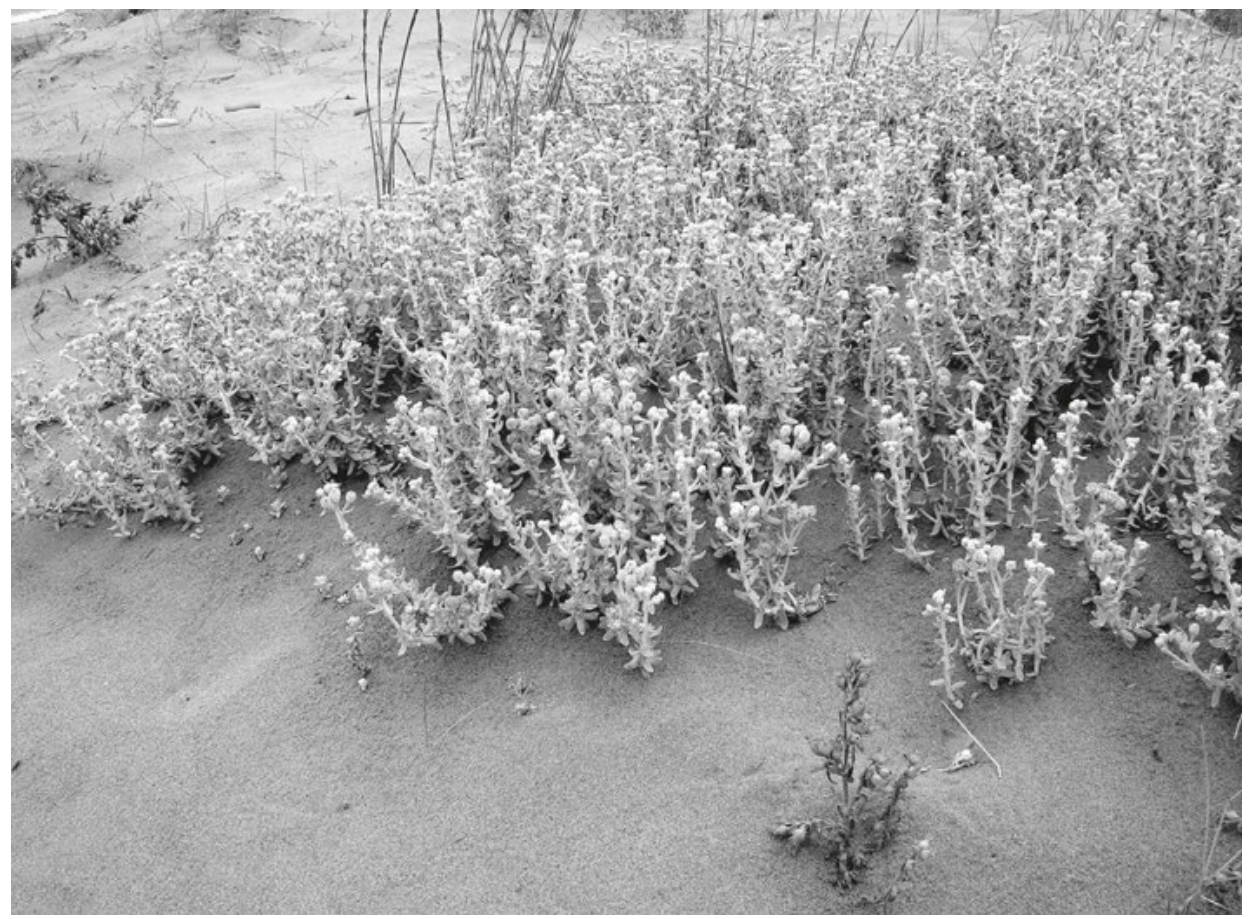

5. La blanquinosa (Otanthus maritimus) a les dunes relictuals de l'Arenal (Foto: els autors).

\section{Biodiversitat}

És una frase que s'escolta amb freqüència: «Ja no se'n veuen tants... com abans». Completeu-la i substituïu-hi els punts per «parotets», «xuplamel-los», i un llarg etcètera. Els qui observem la natura les últimes dècades sabem perfectament que la frase, més que una sospita, és una apreciació inexorablement realista. Malauradament, no disposem de suficients estudis i dades per a quantificar estadísticament i de manera general aqueixa pèrdua de biodiversitat a escala local, però estem davant d'un fenomen indiscutible, generalitzat i paradoxal, perquè representa exactament el revers de la creació d'espais naturals: per una banda, destruïm la natura, però, al mateix temps, invertim recursos per a protegir-la.

Les causes d'aqueixa pèrdua són diverses: contaminació química (insecticides, herbicides, etc.), destrucció física d'hàbitats, introducció d'espècies exòtiques, etc. La regla general és que la degradació de l'hàbitat sempre compromet les poblacions naturals i pot fer minvar o desaparèixer espècies, tot $i$ que algunes demostren ser més resistents $o$ sensibles que altres. En els següents apartats, que no pretenen ser ni de bon tros un catàleg de fauna i flora locals (entre els invertebrats mencionarem només mollluscs i insectes, per a abreujar), farem un repàs succint d'aqueixa biodiversitat, fonamentat principalment en observacions pròpies. 


\subsection{Fauna d'invertebrats}

De mollluscs continentals tenim un parell de citacions clàssiques d'espècies aquàtiques d'aigües dolces incontaminades, que hui s'han extingit: en primer lloc el petxinot de riu (Potomida littoralis f. umbonata) que Rossmassler (1835) cita específicament del Millars i de la séquia Palafanga (aboca al Clot) amb l'antic nom Psilunio littoralis. A més, un caragolet endèmic (Melanopsis dufourii tricarinata fma. subgraellsiana), citat per Azpeitia (1933), és també història passada. Els gasteròpodes terrestres també pateixen una disminució de les poblacions. Cada vegada és més rar encontrar ací el caragol moro (Otala punctata), les vaquetes (Eobania vermiculata) o les caragoles avellanenques (Theba pisana). Quant als mol-luscs marins, tenim dues joies faunístiques davant les nostres costes: la Mitra zonata, i l'escafòpode recentment descobert per a la ciència Antalis caprottii (vegeu Martínez Ortí i Cádiz, 2012).

Els insectes són món a part. Qui no ha patit alguna volta un sobresalt en trobar-se sobtadament una pudenta (Nezara viridula), o una panderola americana (Periplaneta americana), un grill de serres (Anacridium aegyptium) - en fase larvària són de color verd-, una «senyoreta» (Mantis religiosa), un destapaparades (Gryllotalpa gryllotalpa), uns borinots (principalment Xylocopa violacea i Bombus terrestris), etc.? On més varietat hi ha és entre les palometes, els escarabats i les libèlllules.

Els odonats (libèlllules) són magnífics indicadors de la qualitat de les aigües, car el seu cicle reproductiu passa per una fase larvària que viu a les aigües dolces. A Borriana que, fa temps, fou un paradís per a les zones humides, cada volta és més rar poder gaudir de la presència d'aquests fantàstics insectes per l'eutrofització i contaminació de les aigües. La llista que presentem és producte de l'estudi, sumat a l'experiència d'un de nosaltres com a caçador de parotets. El «grill» o pixaví per excel-lència, el més comú, ací és Crocothemis erythraea (el mascle roig i la femella groguenca); els rars espirits (Calopteryx haemorrhoidalis); torerets (Cercion lindeni, Lestes virens, Ischnura elegans i Ceriagrion tenellum); parots (Aeshna mixta, Anax parthenope), més el mític parot blau Anax imperator. Els reis i reines - grills de colorins, d'abdomen fi i cilíndric - rebien aquest nom segons hi predominaren les tonalitats roges (mascles) o groguenques (femelles). Pertanyen al gènere Sympetrum, amb dues espècies: S. fonscolombii, més freqüent i Sympetrum sinaiticum. L'Orthetrum coerulescens - blau-s'hi deixava veure més rarament.

Entre els escarabats (coleòpters) encara són fàcils de veure sobre plantes, per exemple, Lyxus algirus, Hoplia coerulea i Oxythyrea funesta, menjadors de flors, o la marieta (Coccinella septempunctata), devoradora de pugons. Però fa temps que no veiem, a Borriana, escarbats d'aigua ni l'escarbat piloter (Scarabaeus sacer) - deixava rastres fàcils de seguir a les dunes de l'Arenal- ni cucs de llum (Nyctophila reichei), etc. Els més grans i bonics de la nostra fauna són l'escarabat dels pins (Polyphylla fullo) que només hem vist una vegada a la nostra alqueria familiar, l'escarbat rinoceront (Oryctes nasicornis grypus) - les larves viuen a les soques mortes - i l'escarbat daurat (Cetonia aurata) de color verd metàllic.

És indiscutible que cada dia també hi ha menys palometes (lepidòpters). La causa és, com sempre, l'alteració del seu hàbitat. Hui dia, trobar volant pel poble un exemplar de palometa rei (Papilio machaon), o de palometa zebrada (Iphiclides feisthamelii), és tot 
un esdeveniment. No tan rara és la palometa reina (Vanessa atlanta), el satírid Pararge aegeria, o la vulgar palometa de la col (Pieris brassicae). Els heteròcers també han esdevingut rars: la palometa de la mort (Acherontia atropos) o l'esfinx ocel-lat (Smerinthus ocellata), o aqueix borinot silenciós que és la palometa colibrí o bufaforats (Macroglossum stellatarum), etc.

\subsection{Fauna de vertebrats}

La fauna de vertebrats també s'ha vist afectada per un retrocés general d'efectius poblacionals, però encara està ben representada, sobretot pel dinàmic grup de les aus, el de major puixança evolutiva. Fent un repàs dels representants més comuns o més interessants, començant pels mamífers, cal citar les fugisseres musteles (Mustela nivalis) i raboses (Vulpes vulpes), la rara rata de sequiol (Arvicola sapidus), el tímid eriçó (Erinaceus europaeus, E. algirus), etc. I entre els més xicotets, la musaranya (Crocidula russula), el talponet (Microtus duodecimcostatus) i les rates penades (Pipistrellus pipistrellus, Eptesicus serotinus, Nyctalis noctula).

Entre els rèptils, a banda de la tortuga d'aigua normal (Emys orbicularis), també s'ha citat l'espècie Mauremys leprosa del Millars. A més, tenim la sargantana comuna (Podarcis hispanica), el dragó (Tarentola mauritanica), i entre els ofidis, el més gran: la serp verda (Malpolon monspessulanus) que no desdenya trepar als arbres, i l'escurçó d'aigua (Natrix maura).

Dels peixos només citarem l'interessant mossegadoret (Cobitis paludica) del Clot (i del Millars, probablement), l'existència del qual ens va ser comunicada pel colllega Pepe Soler. Entre els sensibles amfibis, el «sapo» comú (Bufo bufo spinosus), cada vegada més escàs, la granota (Rana perezi), i uns «sapets» (Epidalea calamita) que a Borriana s'anomenen «ranocs», a les nits caloroses se'ls sent cantar coralment a les marjals.

La nostra avifauna és exuberant, i no resulta gens fàcil retallar la llista. Tenim rapinyaires com l'arpellot (Buteo buteo), l'arpella (Circus aeruginosus), al Millars, i sobretot, la moixeta (Falco tinnunculus), per tot el terme. Caçadors nocturns com els mussols (Athene noctua i Otus scops) i l'òliba (Tyto alba). Entre les aus de marjal del Millars destaca l'agró blau (Ardea cinerea), les camallongues (Himanthopus himantopus), els esplugabous (Bubulcus ibis), i per tota la voramar, a banda de les gavines, tenim el simpàtic corriol (Charadius alexandrinus). Dels horts de tarongers mencionarem el palput (Upupa epops), la merla (Turdus merula), les tórtores (Streptopelia turtur), la garsa (Pica pica) darrerament desplaçada del secà a l'horta, la cotorra de Kramer (Psittacula krameri) que cria a les palmeres, etc., i, entre els pardalets, el vilero (Passer domesticus), el rossinyol comú (Luscinia megarhynchos), el totestiu (Parus major), el pit-roig (Erithacus rubecula), la cadarnera (Carduelis carduelis), el gafarronet (Serinus serinus), el cuetet (Motacilla alba), etc.

\subsection{Flora}

En els apartats sobre la vegetació i els espais naturals ja hem mencionat algunes espècies interessants de la flora local, amb un percentatge d'un $10 \%$ aproximadament de neòfits, espècies foranes naturalitzades. En un intent de màxima concisió no exempt de 
subjectivitat, citarem només un o dos representants florístics per a cada un dels principals tipus d'hàbitat del terme.

Per a començar, de la flora ornamental destacaríem les Sophora japonica cv. doteana i les Howea forsteriana (kènties) del jardí del Pla. Entre els arbres monumentals tenim l'Eucalyptus globulus de Mascarós, un exemplar gegantesc de Brachychiton populneum a la Tanda; la Sophora japonica 'Pendula' centenària de la finca El Naranjal, i el ficus del Pla, Ficus macrophylla. I si hem de triar dos arbres autòctons, serien l'om o mosquiter negre (Ulmus minor) i el llidoner (Celtis australis). No podem deixar de fer-nos ressò de la devastació patida els darrers anys pel contingent de palmeres canàries del terme (Phoenix canariensis) per culpa del morrut roig.

Representant la flora de les nostres platges de còdols i graves tenim el cascall marí (Glaucium flavum) i el violer marí (Matthiola sinuata) (actualment extint, el 2006 desaparegueren els darrers exemplars). I de la vegetació psammòfila dunar, la blanquinosa (Otanthus maritimus). De la vegetació halòfila costanera triaríem la lletugueta de mar (Limonium angustebracteatum), el donzell marí (Artemisia caerulescens) i la cirialera (Salicornia ramosissima), extingida en la dècada dels 80.

La flora de la marjaleria està bellament representada pel lliri o joligroc (Iris pseudacorus) i la bova (Typha domingensis). De la vegetació submergida, el tresor és la pota de bou (Nymphaea alba). Dues herbàcies característiques de la vegetació del Clot serien la menta o brosseta de riu (Mentha pulegium) i la bardana (Arctium minus).

Finalment, entre les males herbes dels horts de tarongers són d'un simbolisme indefugible la nadaleta (Narcissus tazetta), els ja rars xuplamel·los (Gladiolus italicus) i la cresola (Arum italicum). La popular magreta (Oxalis pes-caprae), espècie exòtica, infestant i expansiva, està sotmesa actualment a mesures de control en les dunes de la Comunitat Valenciana, per obra del Decret 203/2009, on per altra banda s'hi inclouen moltes altres espècies vegetals presents al nostre terme.

\section{BIBLIOGRAFIA}

ANDRÉs, J. (1991): «Los moluscos de nuestra costa», Burriana en su historia, vol. II, Borriana, Magnífico Ayuntamiento de Burriana, 545-553.

AzPeitia, F. (1933): «Conchas bivalvas de agua dulce de España y Portugal», Memorias del Instituto Geológico y Minero de España, 38 (vol. 1) 1-458; 39 (vol. 2) 459-763.

BAIXERAs, J., i altres (2006): «Les libèlllules de la Comunitat Valenciana», València. Conselleria de Territori i Habitatge de la Generalitat Valenciana.

Castany, J. (2007 i següents): Estudis de l'avifauna del Clot, patrocinats per l'Ajuntament, Borriana, Ajuntament de Borriana.

Collado, V. i R. Pardo (1985): Fauna ornitológica del término de Burriana, Borriana, Magnífic Ajuntament de Borriana.

GASULL, L. (1971): «Fauna malacológica de las aguas continentales dulces y salobres del Sudeste Ibérico», Boletín de la Sociedad de Historia Natural de Baleares, 16, 23-82.

- (1975): «Fauna malacológica terrestre del Sudeste Ibérico», Bol. Soc. Hist. Nat. Baleares, 20, 5-148. - (1981): «Fauna malacológica terrestre y de agua dulce de la provincia de Castellón de la Plana», Bol. Soc. Hist. Nat. Baleares, 25, 55-102.

Martí de Viciana, R. (1564): Crónica de la Ínclita y Coronada Ciudad de Valencia. Tercera parte, Edició facsímil de la Sociedad Valenciana de Bibliófilos, 1882. 
Martínez-Ortí, A. i L. CÁdiz (2012): «Living scaphopods from de Valencian coast (E Spain) and description of Antalis caprottii n. sp. (Dentalidae)», Animal Biodiversity and Conservation, vol. 35, núm. 1, Museo de Ciencias Naturales de Barcelona.

Monrós, G. i altres (1990): «Estudi químic de la dinàmica de les aigües litorals del Delta del Millars a l'estiu 1989», Anuari de l'Agrupació Borrianenca de Cultura, 1, 107-121.

Navarro, L. (1991): «La paleovegetación a través del análisis polínico», Burriana en su historia, II, Borriana, Magnífico Ayuntamiento de Burriana, 13-27.

Ortells, V.M. (1987): «El marco natural: una aproximación», Burriana en su historia, I, Borriana, Magnífico Ayuntamiento de Burriana, 13-18.

Pardo, R. (1984): Las aves del naranjal de la provincia de Castellón, Castelló, Publicaciones del Seminario de Estudios Económicos y Sociales de la Caja de Ahorros y Monte de Piedad de Castellón.

Peris, R. i altres (1985): «La desembocadura del Mijares: "Les Goles"», Itinerarios ecológicos, 11-57.

Roselló, R. (1988): Catálogo florístico y vegetación del término municipal de Borriana, Borriana, Agrupació Borrianenca de Cultura / Ajuntament de Borriana.

- (1990): «Mollluscs continentals a Borriana», Anuari de l'Agrupació Borrianenca de Cultura, 1, $139-147$.

- (1991): «Flora y vegetación», Burriana en su historia, vol. II, Borriana, Magnífico Ayuntamiento de Burriana, 555-583.

- (1997): «Benvinguda Mrs. Kramer», Butlletí d'Informació Municipal El Pla, 212, 12.

- (2003): «El terme de Borriana en temps de Viciana», Miscellània Homenatge a Rafael Martí de Viciana en el V centenari del seu naixement 1502-2002, Borriana, Magnífic Ajuntament de Borriana, 362-369.

- (2004): «SOS per la blanquinosa», Buris-ana, 193,19-20.

- (2005a): «Dues interessants mostres de vegetació», Buris-ana, 196, 6-9.

- (2005b): «Limonium angustebracteatum Erben, a Borriana», Buris-ana, 197, 10-13.

- (2007): Estudi botànic de l'Estany de la Vila (Borriana). Dades per a la seua gestió mediambiental, Borriana, Magnífic Ajuntament de Borriana.

- (2008a): «Forasters vindran... que a casa es quedaran», Buris-ana, 205, 21-25.

- (2008b): «Flora rupícola borrianenca», Buris-ana, 206, 25-28.

Roselló, R. i J.B. Peris (1990): «Algunos neófitos de la provincia de Castellón», Fontqueria , 28, 53-56. - (1991): «De Plantis Castellonensibus», Fontqueria , 31,149-151.

RossmassLer, E.A. (1835-39): Iconographie der Land un Süsswasser Mollusken, Dresden-Leipzig.

SOROLla, F. (2008): «Les raboses han tornat», Buris-ana, 204,21-22.

VIÑALS, M.J. (2004): «Repercussions de l'acció antròpica a les albuferes, marjals i altres zones humides costaneres valencianes», dins LAPEÑA, L., i I. QUERAL (eds.): Preservar l'aigua, conservar la vida: un compromís social i ambiental, Borriana, Agrupació Borrianenca de Cultura, 15, 109-129.

\section{BIONOTES}

\section{Andrea Rosselló Planelles}

Llicenciada en Biologia per la Universitat de València, ha exercit com a professora de Biologia i actualment treballa al banc de larves de la piscifactoria de Borriana.

\section{Robert Roselló Gimeno}

Catedràtic d'institut jubilat. Doctor en Biologia per la Universitat de València, actualment forma part d'un equip d'investigació sobre temes de la seua especialitat (vegetació i flora mediterrània) centrada en diversos gèneres de labiades com ara Teucrium, Sideritis i Thymus. 